\title{
Research on the Comprehensive Evaluation Model of the Lateral Stability of Tractor-semitrailer
}

\author{
Bin Tang ${ }^{1, a}$, Wei Zhou ${ }^{2, b^{*}}$ and Guosheng Zhang ${ }^{3, c}$ \\ ${ }^{1,2,3}$ Research Institute of Highway, Ministry of Transport \\ Beijing 100088, China \\ atangbin5700@163.com, ${ }^{\text {b }}$ w.zhou@rioh.cn, ${ }^{\mathrm{c}}$ gs.zhang@rioh.cn
}

Keywords: Tractor-semitrailer; Lateral stability; Simulation experiments; Uniform design; Comprehensive evaluation model

\begin{abstract}
Tractor-semitrailer is the dominant vehicle model of road transportation, whose lateral stability during transportation has always attracted plenty of attention. Based on the TruckSim simulation software, a dynamic model of the tractor semitrailer was established. Then, the lateral stability simulation experiments were designed by using uniform design method. By using SPSS, MATLAB software, the results were analyzed and the prediction models of the experiment indexes were established, based on which the comprehensive evaluation model of the lateral stability of tractor-semitrailer was eventually established.
\end{abstract}

\section{Introduction}

Due to the acceleration of the process of economic development, transportation industry has entered a new period of development, in which road transportation has occupied an important position. Tractor-semitrailer with large loading capacity and high transport efficiency, undertakes most of the road transportation tasks and its problems of safety accidents have also received extensive attention. Lateral stability is one of the main active safety performance of the tractor-semitrailer [1,2].Therefore, how to study and evaluate the lateral stability, in order to obtain good active safety performance, has important significance.

The lateral stability of tractor-semitrailer refers to the performance of lateral resistance to external interference (such as side wind, pavement roughness, micro bend curvature etc.) to keep straight driving [3]. In this paper, a type of tractor-semitrailer was set as the research object. By means of simulation, combined with experimental design and data analysis software, the comprehensive evaluation model of the lateral stability of tractor-semitrailer was eventually established to provide a theoretical basis for the evaluation of lateral stability of tractor-semitrailer.

\section{The Establishment and Validation of Simulation Model}

The establishment of simulation model. TruckSim is a kind of dynamic simulation software used for dynamic simulation of vehicle dynamics and it is developed by the American Mechanical Simulation Corporation [4]. As vehicle performance analysis software, modeling and simulation 
process is very simple and the output curve is clear and easy to read. Besides, it has the real-time simulation function $[5,6]$. TruckSim has become a powerful tool for many automobile manufacturers and research institutes and it is widely used in the design and development of the modern automobile system.

Tractor-semitrailer consisting of a 4250 type $6 \times 4$ tractor and three axis van semi-trailer was taken as the research object in this paper. Parametric modeling was built based on the TruckSim, including body modeling, tire system modeling and steering system modeling etc. The vehicle and simulation modeling interface are shown in Fig. 1.

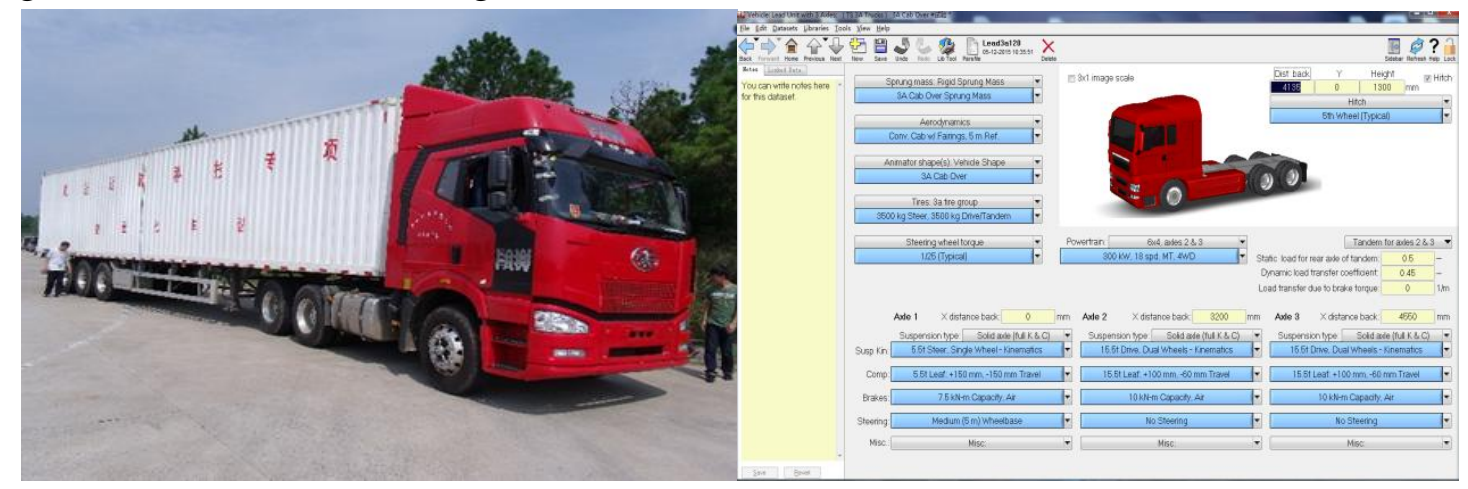

Fig. 1 The real vehicle (left) and the modeling interface (right)

The validation of simulation model. Validity of the tractor-semitrailer model was verified by steady static circular experiment. The stable speed of the vehicle was set to $30 \mathrm{~km} / \mathrm{h}$, which was traveling in the radius of $25 \mathrm{~m}$. The experiment equipment were mainly composed of VBOX3, gyroscope, automobile steering force angle measuring instrument, data acquisition module and PC etc. Experiment conditions of the simulation experiment and real vehicle experiment were consistent. Contrast curves of the real tractor experiment data after treatment and simulation experiment data are shown from Fig. 2 to Fig. 4.
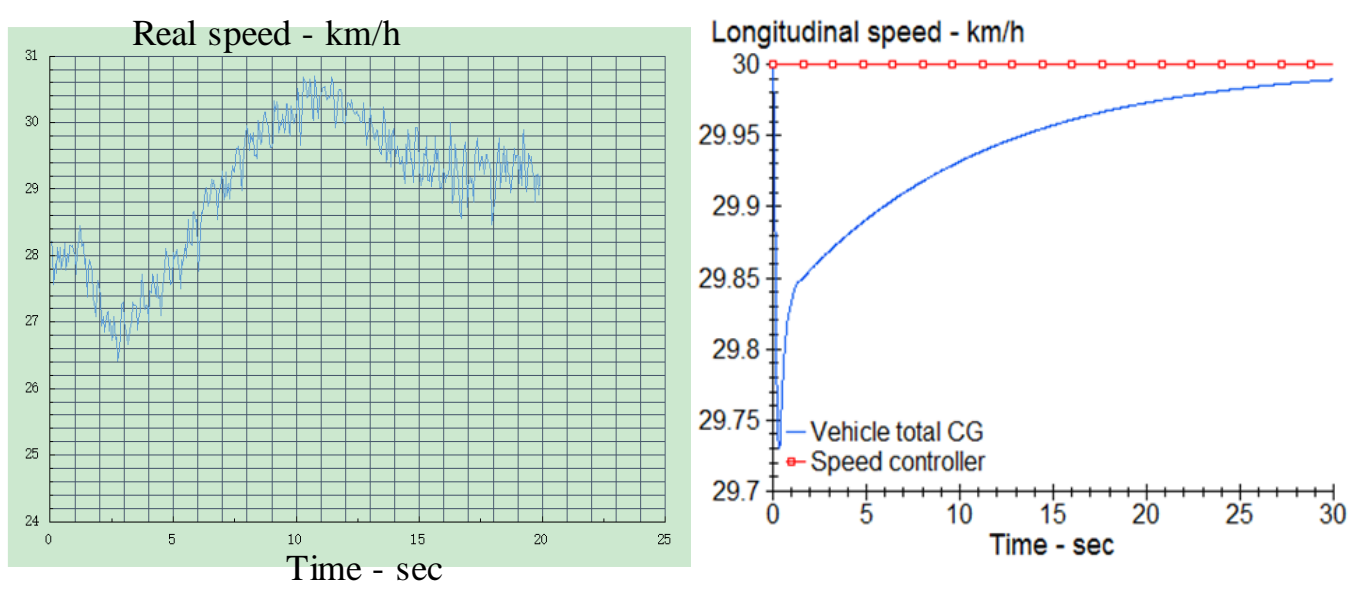

Fig. 2 The speed of real vehicle (left) and the speed of simulation model (right)

Lateral acceleration - g's 

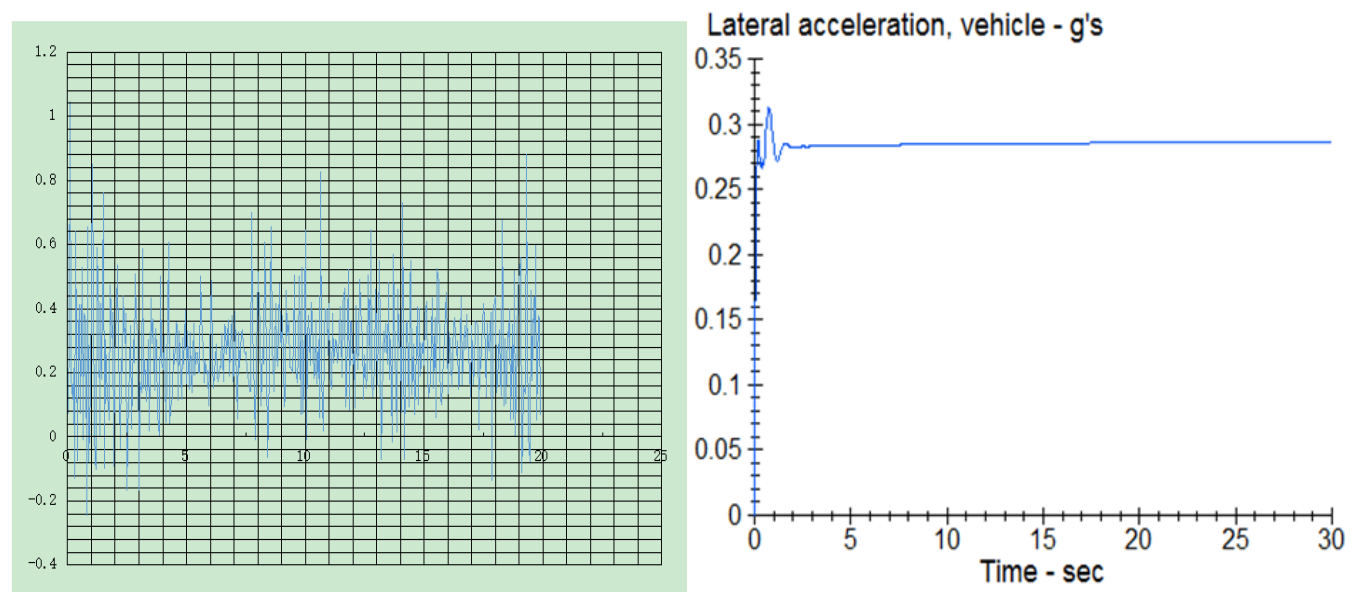

Fig. 3 The lateral acceleration of real vehicle (left) and the lateral acceleration of simulation model (right)
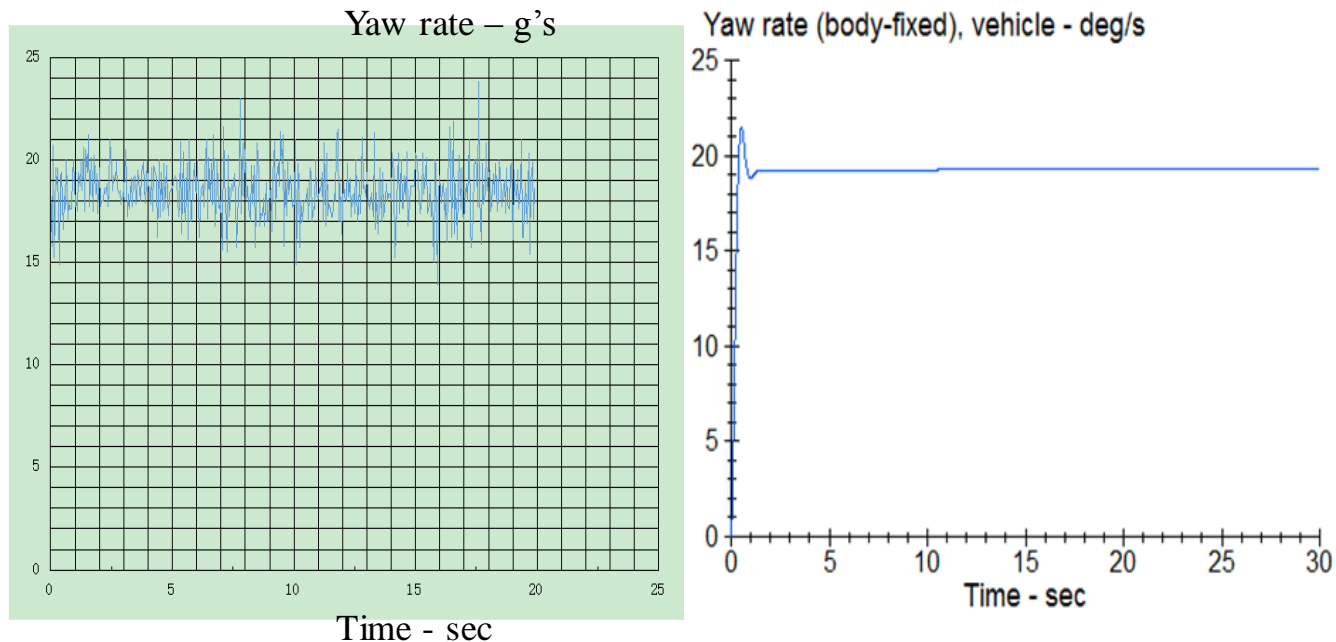

Fig. 4 The yaw rate of real vehicle (left) and the yaw rate of simulation model (right)

As is shown in Fig. 2, the speed fluctuation of the real vehicle is relatively large, and its stable speed is about $29 \mathrm{~km} / \mathrm{h}$. The stable speed of simulation model is about $29.9 \mathrm{~km} / \mathrm{h}$. The error between the two is $3.1 \%$. As is shown in Fig. 3, the stable lateral acceleration of the real vehicle is about $0.267 \mathrm{~g}$, while the stable lateral acceleration of simulation model is about $0.28 \mathrm{~g}$. The error between the two is $4.9 \%$.From Fig. 4, the yaw rate of the real vehicle is stable at about $18.8 \mathrm{deg} / \mathrm{s}$, while the yaw rate of simulation model is stable at $19.3 \mathrm{deg} / \mathrm{s}$. The error between the two is $2.7 \%$. By comparing the data results of real vehicle experiment and simulation experiment, the errors of the speed, lateral acceleration and yaw rate between the two vehicles are all below 5\%, which indicates the simulation model has good accuracy and consistency, and can be used to study the lateral stability of tractor-semitrailer simulation experiments.

\section{Uniform Experimental Design and Regression Analysis}

Uniform experimental design. To study the lateral stability of the tractor-semitrailer, the vehicle parameters were set as the experiment factor, in this paper, to investigate the influence of different levels of factors for the evaluation indexes of lateral stability. Considering the influence factors involved and changing range, etc., the uniform designing method was used for the optimal design.

The uniform designing is an experiment designing method based on the orthogonal designing, especially for multi-factor and multi- level experiments [7]. Experiments were arranged according to the uniform designing form, and eight experimental factors chosen in the experiments were tractor 
rotation inertia IZ1, tractor centroid height $\mathrm{H} 1$, tractor wheelbase $\mathrm{L} 1$, position of hitch $\mathrm{P}$, trailer payload mass $\mathrm{M}$, height of load centroid $\mathrm{H} 2$, mass center of the load $\mathrm{D}$, spring rate $\mathrm{K}$, respectively. In order to make the level of experimental factors horizontal and sufficiently uniform, U15 (158) table was used in the experimental design. The experimental arrangements are shown in Table 1 (initial levels of the factors have been marked). The experiment indexes were selected as maximum of tractor yaw rate $\mathrm{y} 1 \mathrm{~h}$, maximum of semi-trailer yaw rate $\mathrm{y} 2 \mathrm{~h}$, posterior amplification coefficient of yaw rate $y h R$, maximum of tractor lateral acceleration ylc, maximum of semi-trailer lateral acceleration y2c, posterior amplification coefficient of lateral acceleration ycR, hitch articulation yj, hitch articulation rate yjr.

TABLE 1 Uniform experimental design

\begin{tabular}{|c|c|c|c|c|c|c|c|c|}
\hline $\begin{array}{c}\text { Factors } \\
\text { Number }\end{array}$ & $\begin{array}{c}\mathbf{I}_{\mathbf{Z 1}} \\
\left(\mathbf{k g}-\mathbf{m}^{\mathbf{2}}\right)\end{array}$ & $\begin{array}{c}\mathbf{H}_{\mathbf{1}} \\
(\mathbf{m m})\end{array}$ & $\begin{array}{c}\mathbf{L}_{\mathbf{1}} \\
(\mathbf{m m})\end{array}$ & $\begin{array}{c}\mathbf{P} \\
(\mathbf{m m})\end{array}$ & $\begin{array}{c}\mathbf{M} \\
(\mathbf{k g})\end{array}$ & $\begin{array}{c}\mathbf{H}_{\mathbf{2}} \\
(\mathbf{m m})\end{array}$ & $\begin{array}{c}\mathbf{D} \\
(\mathbf{m m})\end{array}$ & $\begin{array}{c}\mathbf{K} \\
(\mathbf{N} / \mathbf{m m})\end{array}$ \\
\hline 1 & 21185.3 & 880 & 3080 & 4105 & 30000 & 2390 & 7800 & 2800 \\
\hline 2 & 21285.3 & 920 & 3200 & 4315 & 26500 & 2270 & 7600 & 2750 \\
\hline 3 & 21385.3 & 960 & 3320 & 4075 & 30500 & 2150 & 7400 & 2700 \\
\hline 4 & 21485.3 & 1000 & 2990 & 4285 & 27000 & 2480 & 7200 & 2650 \\
\hline 5 & 21585.3 & 1040 & 3110 & 4045 & 31000 & 2360 & 7000 & 2600 \\
\hline 6 & 21685.3 & 1080 & 3230 & 4255 & 27500 & 2240 & 6800 & 2550 \\
\hline 7 & 21785.3 & 1120 & 3350 & 4015 & 31500 & 2120 & 6600 & 2500 \\
\hline 8 & 21885.3 & 860 & 3020 & 4225 & 28000 & 2450 & 7900 & 2450 \\
\hline 9 & 21985.3 & 900 & 3140 & 3985 & 32000 & 2330 & 7700 & 2400 \\
\hline 10 & 22085.3 & 940 & 3260 & 4195 & 28500 & 2210 & 7500 & 2350 \\
\hline 11 & 22185.3 & 980 & 3380 & 3955 & 32500 & 2090 & 7300 & 2300 \\
\hline 12 & 22285.3 & 1020 & 3050 & 4165 & 29000 & 2420 & 7100 & 2250 \\
\hline 13 & 22385.3 & 1060 & 3170 & 3925 & 33000 & 2300 & 6900 & 2200 \\
\hline 14 & 22485.3 & 1100 & 3290 & 4135 & 29500 & 2180 & 6700 & 2150 \\
\hline 15 & 22585.3 & 1140 & 3410 & 4345 & 33500 & 2510 & 8000 & 2850 \\
\hline
\end{tabular}

Regression analysis of the results. With reference to the experimental requirements of GB/T 25979 [8], single sine angle was input for the simulation experimental conditions, and parameters of the vehicle model were set according to the level of experimental factors in Table 1, then 15 simulation experiments were carried out and the values of the evaluation indexes were calculated. The results of the simulation experiments are shown in Table 2.

TABLE 2 The statistical results of simulation experiments

\begin{tabular}{|c|c|c|c|c|c|c|c|c|}
\hline Number & $\boldsymbol{y}_{\boldsymbol{h} \boldsymbol{h}}$ & $\boldsymbol{y}_{\boldsymbol{h} \boldsymbol{h}}$ & $\boldsymbol{y}_{\boldsymbol{h} \boldsymbol{R}}$ & $\boldsymbol{y}_{\boldsymbol{l c}}$ & $\boldsymbol{y}_{\boldsymbol{c} \boldsymbol{c}}$ & $\boldsymbol{y}_{\boldsymbol{c} \boldsymbol{R}}$ & $\boldsymbol{y}_{\boldsymbol{j}}$ & $\boldsymbol{y}_{\boldsymbol{j} \boldsymbol{r}}$ \\
\hline 1 & 6.6566 & 6.3187 & 0.9492 & 0.23659 & 0.24104 & 1.0188 & 2.735 & 2.9889 \\
\hline 2 & 6.5102 & 6.1784 & 0.9490 & 0.23241 & 0.23554 & 1.0135 & 2.7109 & 3.0186 \\
\hline 3 & 6.501 & 6.1114 & 0.9401 & 0.23098 & 0.23346 & 1.0107 & 2.5544 & 2.8124 \\
\hline 4 & 5.1155 & 4.7193 & 0.9225 & 0.18159 & 0.18177 & 1.0010 & 2.1084 & 2.3597 \\
\hline 5 & 5.9271 & 5.5127 & 0.9301 & 0.21168 & 0.21285 & 1.0055 & 2.3414 & 2.6144 \\
\hline 6 & 5.8528 & 5.436 & 0.9288 & 0.20387 & 0.20966 & 1.0284 & 2.3505 & 2.6583 \\
\hline 7 & 5.9806 & 5.5292 & 0.9245 & 0.21082 & 0.21399 & 1.0150 & 2.2744 & 2.5391 \\
\hline
\end{tabular}




\begin{tabular}{|c|c|c|c|c|c|c|c|c|}
\hline 8 & 6.5387 & 6.1966 & 0.9477 & 0.23232 & 0.23644 & 1.0177 & 2.7538 & 2.9993 \\
\hline 9 & 6.6549 & 6.2738 & 0.9427 & 0.23522 & 0.23992 & 1.0200 & 2.6546 & 2.8697 \\
\hline 10 & 6.5669 & 6.1896 & 0.9425 & 0.23378 & 0.23636 & 1.0110 & 2.6571 & 2.909 \\
\hline 11 & 6.3312 & 5.8809 & 0.9289 & 0.22281 & 0.22552 & 1.0122 & 2.4005 & 2.6497 \\
\hline 12 & 5.5929 & 5.1793 & 0.9260 & 0.19712 & 0.19996 & 1.0144 & 2.2613 & 2.5282 \\
\hline 13 & 6.091 & 5.5872 & 0.9173 & 0.21203 & 0.21676 & 1.0223 & 2.3168 & 2.5561 \\
\hline 14 & 5.9547 & 5.5754 & 0.9363 & 0.21328 & 0.21549 & 1.0104 & 2.3571 & 2.6159 \\
\hline 15 & 6.7911 & 6.454 & 0.9504 & 0.23957 & 0.24806 & 1.0354 & 2.7634 & 2.9086 \\
\hline
\end{tabular}

Experimental data is to be analyzed after the experiment, and the method of multiple regression analysis is usually adopted for the experimental results, causing uniform design is not comparable and regular, and the method of orthogonal experiment analysis is not suitable [9]. Before the regression analysis, the SPSS is used to preparatively analyze the experimenting results, and the correlation analysis results show that the factors of greater linear correlation to the experimental indexes are tractor centroid height $\mathrm{H} 1$, tractor wheelbase L1, trailer payload mass M, mass center of the load $\mathrm{D}$ and spring rate $\mathrm{K}$.

Because the experimental factors involved in this study are the vehicle parameters, of which the dimensions are not uniform, thus normalization is necessary to facilitate regression analysis. The normalized value is the ratio of the actual level to the average level of the factors, and $\mathrm{x} 1, \mathrm{x} 2, . . \mathrm{x} 8$ represent the value of each experimental factor after normalized. The values of $\mathrm{x} 2, \mathrm{x} 3, \mathrm{x} 5, \mathrm{x} 7$ are as follows (Eq. 1):

$$
x_{2}=X_{2} / 1000, x_{3}=X_{3} / 3200, x_{5}=X_{5} / 30000, x_{7}=X_{7} / 7300, x_{8}=X_{8} / 2500
$$

In the above, X2 represents the actual value of $\mathrm{H} 1, \mathrm{X} 3$ represents the actual value of $\mathrm{L} 1, \mathrm{X} 5$ represents the actual value of $M, X 7$ represents the actual value of $D, X 8$ represents the actual value of $\mathrm{K}$.

Since linear relationship does not exist between the experimental factors and experimental indexes, it is essential to establish multiple nonlinear regression equation. In this research, multivariate quadratic equations are used to establish prediction models, without considering the terms of interaction factors, the expression of regression model is as follow Eq. 2:

$$
y=b_{0}+b_{2} x_{2}+b_{3} x_{3}+b_{5} x_{5}+b_{7} x_{7}+b_{8} x_{8}+b_{22} x_{2}^{2}+b_{33} x_{3}^{2}+b_{55} x_{5}^{2}+b_{77} x_{7}^{2}+b_{88} x_{8}^{2}
$$

Based on the model, the evaluation indexes of lateral stability are analyzed by SPSS, with the method of backward. Through the test of significance, insignificant items are excluded, and the regression prediction models of evaluation indexes are as follows (Eq. 3 to Eq. 10):

The regression prediction model of $\mathrm{ylh}$

$$
y_{1 h}=-98.932-39.544 x_{2}+239.485 x_{3}+1.356 x_{5}+18.892 x_{2}^{2}-117.07 x_{3}^{2}+2.062 x_{7}^{2}
$$

(2) The regression prediction model of $y_{2 h}$

$$
y_{2 h}=-101.445-42.792 x_{2}+246.807 x_{3}+0.972 x_{5}+20.581 x_{2}^{2}-120.673 x_{3}^{2}+2.395 x_{7}^{2}
$$

(3) The regression prediction model of $y_{h R}$

$$
y_{h R}=\frac{-101.445-42.792 x_{2}+246.807 x_{3}+0.972 x_{5}+20.581 x_{2}^{2}-120.673 x_{3}^{2}+2.395 x_{7}^{2}}{-98.932-39.544 x_{2}+239.485 x_{3}+1.356 x_{5}+18.892 x_{2}^{2}-117.07 x_{3}^{2}+2.062 x_{7}^{2}}
$$


(4) The regression prediction model of $y_{1 c}$

$$
y_{1 c}=-3.435-1.44 x_{2}+8.397 x_{3}+0.039 x_{5}+0.686 x_{2}^{2}-4.1 x_{3}^{2}+0.074 x_{7}^{2}
$$

(5) The regression prediction model of $y_{2 c}$

$$
y_{2 c}=-3.877-1.636 x_{2}+9.437 x_{3}+0.043 x_{5}+0.792 x_{2}^{2}-4.621 x_{3}^{2}+0.087 x_{7}^{2}
$$

(6) The regression prediction model of $y_{c R}$

$$
y_{c R}=\frac{-3.877-1.636 x_{2}+9.437 x_{3}+0.043 x_{5}+0.792 x_{2}^{2}-4.621 x_{3}^{2}+0.087 x_{7}^{2}}{-3.435-1.44 x_{2}+8.397 x_{3}+0.039 x_{5}+0.686 x_{2}^{2}-4.1 x_{3}^{2}+0.074 x_{7}^{2}}
$$

(7) The regression prediction model of $y_{j}$

$$
y_{j}=-43.142-19.463 x_{2}+107.032 x_{3}+9.553 x_{2}^{2}-52.836 x_{3}^{2}+1.349 x_{7}^{2}
$$

(8) The regression prediction model of $y_{j r}$

$$
y_{j r}=-47.284-19.154 x_{2}+116.214 x_{3}+9.335 x_{2}^{2}-57.283 x_{3}^{2}-0.246 x_{5}^{2}+1.175 x_{7}^{2}
$$

\section{The Establishment of Comprehensive Evaluation Model}

The establishme nt of experimental index scoring evaluation model. After prediction models of experimental indexes to characterize lateral stability are established, the evaluation method of each index in QC/T 480 [10] is used for reference. According to the constraint range of the uniform experimental table above, program is compiled with MATLAB to get maximum and minimum of each prediction model which is shown in Table 3.

TABLE 3 Maximum and minimum of each prediction model

\begin{tabular}{|c|c|c|}
\hline Prediction model & Maximum & Minimum \\
\hline$y_{l h}(\mathrm{deg} / \mathrm{s})$ & 7.4993 & 4.8184 \\
\hline$y_{2 h}(\mathrm{deg} / \mathrm{s})$ & 7.1331 & 4.3840 \\
\hline$y_{h R}$ & 0.9641 & 0.8970 \\
\hline$y_{l c}\left(\mathrm{~m} / \mathrm{s}^{2}\right)$ & $0.2658 \mathrm{~g}$ & $0.1707 \mathrm{~g}$ \\
\hline$y_{2 c}\left(\mathrm{~m} / \mathrm{s}^{2}\right)$ & $0.2724 \mathrm{~g}$ & $0.1705 \mathrm{~g}$ \\
\hline$y_{c R}$ & 1.0470 & 0.9912 \\
\hline$y_{j}(\mathrm{deg})$ & 3.0101 & 1.9266 \\
\hline$y_{j r}(\mathrm{deg} / \mathrm{s})$ & 3.3098 & 2.1206 \\
\hline
\end{tabular}

Hereafter, the scoring evaluation models of experimental indexes can be established as follows (Eq. 11 to Eq. 18):

(1)Scoring evaluation model of $y_{1 \mathrm{~h}}$

$$
A_{1}=60+\frac{7.4993-y_{1 h}}{7.4993-4.8184} \times 40=60+\frac{7.4993-y_{1 h}}{2.6809} \times 40
$$

(2) Scoring evaluation model of $y_{2 h}$

$$
A_{2}=60+\frac{7.1331-y_{2 h}}{7.1331-4.3840} \times 40=60+\frac{7.1331-y_{2 h}}{2.7491} \times 40
$$

(3) Scoring evaluation model of $y_{h R}$ 


$$
A_{R}=60+\frac{y_{h R}-0.8970}{0.9641-0.8970} \times 40=60+\frac{y_{h R}-0.8970}{0.0671} \times 40
$$

(4) Scoring evaluation model of $y_{1 c}$

$$
B_{1}=60+\frac{0.2658 g-y_{1 c}}{0.2658 g-0.1707 g} \times 40=60+\frac{0.2658 g-y_{1 c}}{0.0951 g} \times 40
$$

(5) Scoring evaluation model of $y_{2 c}$

$$
B_{2}=60+\frac{0.2724 g-y_{2 c}}{0.2724 g-0.1705 g} \times 40=60+\frac{0.2724 g-y_{2 c}}{0.1019 g} \times 40
$$

(6) Scoring evaluation model of $y_{c R}$

The minimum of the posterior amplification coefficients of lateral acceleration is 0.9912 , which means the posterior amplification coefficients of lateral acceleration are not always showed a trend of amplification and a little shrink trend exists. The model can be established as follow:

$$
B_{R}=60+\frac{0.047-\left|y_{c R}-1\right|}{1.0470-1} \times 40=60+\frac{0.047-\left|y_{c R}-1\right|}{0.047} \times 40
$$

(7) Scoring evaluation model of $y_{j}$

$$
C=60+\frac{3.0101-y_{j}}{3.0101-1.9266} \times 40=60+\frac{3.0101-y_{j}}{1.0835} \times 40
$$

(8) Scoring evaluation model of $y_{j r}$

$$
C_{r}=60+\frac{3.3098-y_{j r}}{3.3098-2.1206} \times 40=60+\frac{3.3098-y_{j r}}{1.1892} \times 40
$$

The establishment of comprehensive evaluation model. All the scoring evaluation models of experimental indexes were selected to establish the comprehensive evaluation model of lateral stability, including scoring evaluation models of maximum of tractor yaw rate $\mathrm{ylh}$, maximum of semi-trailer yaw rate $\mathrm{y} 2 \mathrm{~h}$, posterior amplification coefficient of yaw rate $\mathrm{yhR}$, maximum of tractor lateral acceleration $\mathrm{y} 1 \mathrm{c}$, maximum of semi-trailer lateral acceleration $\mathrm{y} 2 \mathrm{c}$, posterior amplification coefficient of lateral acceleration ycR, hitch articulation yj and hitch articulation rate yjr. The expression of comprehensive evaluation model is as follow (Eq. 19):

$$
W=60+\left(\begin{array}{l}
\frac{7.4993-y_{1 h}}{2.6809}+\frac{7.1331-y_{2 h}}{2.7491}+\frac{y_{h R}-0.8970}{0.0671}+\frac{0.2658 g-y_{1 c}}{0.0951 g}+ \\
\frac{0.2724 g-y_{2 c}}{0.1019 g}+\frac{0.047-\left|y_{c R}-1\right|}{0.047}+\frac{3.0101-y_{j}}{1.0835}+\frac{3.3098-y_{j r}}{1.1892}
\end{array}\right) \times \frac{40}{8}
$$

According to the comprehensive evaluation model and constraint range of factors' levels, the maximum and minimum score of the model is calculated as 95 and 67. To evaluate the lateral stability of tractor-semitrailer directly, the scoring interval of the comprehensive evaluation model is divided into 5 grades (excellent, good, general, poor, very poor). The specific evaluation is shown in Table 4. 
TABLE 4 The evaluation of performance grade

\begin{tabular}{|c|c|}
\hline Scoring & Grade \\
\hline $90 \sim 95$ & Excellent \\
\hline $84 \sim 89$ & Good \\
\hline $78 \sim 83$ & General \\
\hline $72 \sim 77$ & Poor \\
\hline $67 \sim 71$ & Very Poor \\
\hline
\end{tabular}

\section{Conclusions}

Tractor-semitrailer has been playing a significant role in road transportation, meanwhile, with safety accidents occurred occasionally. Researches on the lateral stability in driving have become an important research topic in the field of automotive safety. Based on the simulation model established by TruckSim, uniform simulation experiments were carried out. Through the data analysis of SPSS and MATLAB, the scoring evaluation models of experimental indexes were established, based on which the comprehensive evaluation model of the lateral stability was eventually established to provide a theoretical basis for the evaluation of the lateral stability of tractor-semitrailer. Furthermore, according to the comprehensive evaluation model, main parameters can be adjusted to improve the lateral stability of tractor-semitrailer.

\section{References}

[1]XU Yan, LIU Hong-fei, REN You, PENG Tao. Analysis on the trajectory of the tractor-semitrailer in crook circumstance $[\mathrm{J}]$. Journal of Changchun University of Science and Technology (Natural Science Edition), 2008, 31(1):132-134.

[2]ZHANG Jian-guo. Research on driving stability of tractor-semitrailer based on closed loop control [D]. The doctoral dissertation of Jilin University, 2010.

[3]XU Hong-guo, LIU Hong-fei, YU Zeng-liang. Overview of tractor-trailer lateral stability study [J]. Journal of Highway and Transportation Research and Development, 2006, 23(2):141-146.

[4]JIANG Zu-xiao. Vehicle dynamics modeling and simulation analysis of heavy-duty truck based on trucksim [D]. The master degree thesis of Jilin University, 2009.

[5]HAN Shu-cang. The simulation of controllability and stability of tractor-semitrailer and its braking performance based on trucksim [D]. The master degree thesis of Jilin University, 2012.

[6]XU Yan. Dynamics modeling and simulation assessment of operating bus chassis performance based on trucksim [D]. The master degree thesis of Jilin University, 2012.

[7]LIANG Yi-zeng, FANG Kai-tai, XU Qing-song. Uniform design and its application sin chemistry and chemical engineering [J].Chemo metrics and Intelligent Laboratory Systems, 2001, 58(1):43-57.

[8]GB/T 25979-2010/ISO 14791:2000. Road vehicles heavy commercial vehicle combinations and articulated buses lateral stability test methods[S]. Beijing: China Standard Press, 2010.

[9]HE Wei, XUE Wei-dong, TANG Bin. The optimization design method and test data analysis [M]. Beijing: Chemical Industry Press, 2014.

[10]QC/T 480-1999. Vehicle handling stability index limits and evaluation method[S]. Beijing: China Standard Press, 1999. 